\title{
O MOVIMENTO INTERFÓRUNS DE EDUCAÇÃO INFANTIL DO BRASIL (MIEIB) E SEUS EFEITOS NAS POLÍTICAS PÚBLICAS
}

\author{
Janaina Vargas de Moraes Maudonnet ${ }^{1}$
}

\begin{abstract}
RESUMO: Este artigo analisa como o Movimento Interfóruns de Educação Infantil do Brasil (MIEIB) incidiu nas políticas públicas da área. Discute-se como o movimento é organizado, suas estratégias, avanços e desafios na relação com o governo federal ao longo de seus 20 anos. A coleta de dados se deu por meio de pesquisa documental e entrevista em profundidade. Destacam-se as teorias sobre as consequências dos movimentos sociais nas políticas públicas, de autores como Edward Amenta, Alberto Melucci e Theda Skocpol, entre outros. Conclui-se que as possibilidades de influência dos movimentos sociais nas políticas são marcadas pelas relações socioestatais estabelecidas, que são variáveis dependendo dos objetivos e capacidades de ação, tanto do Estado quanto do movimento social.
\end{abstract}

Palavras-chave: Movimentos Sociais. Movimento Interfóruns de Educação Infantil do Brasil. Políticas Públicas. Educação Infantil. Interações Socioestatais.

\section{EFFECTS OF THE “MOVIMENTO INTERFÓRUNS DE EDUCAÇÃO INFANTIL DO BRASIL (MIEIB)" ON PUBLIC POLICIES}

\begin{abstract}
The purpose of this article is to analyze how the "Movimento Interfóruns de Educação Infantil do Brasil (MIEIB)" affected public policies in the Early Childhood Education. It discusses how the movement is organized, its strategies, advances, and challenges in its relationship with the Federal Government throughout its 20 years. The data were collected through documentary research and interview with activists. This work highlights theories that discuss the consequences of social movements on public policies, of authors as Edward Amenta, Alberto Melucci e Theda Skocpol, among others. It is concluded that the possibilities of the incidence of social movements in politics are marked by the established socio-state relations, which vary depending on the combination of objectives and capacities of both the State and the social movement.
\end{abstract}

Keywords: Social Movements. Movimento Interfóruns de Educação Infantil do Brasil. Early Childhood Education. Public Policies. State-Society Relations.

1.Universidade de São Paulo - Faculdade de Educação - São Paulo (SP), Brasil. E-mail: janaina.maudonnet@gmail.com Este artigo é resultante das pesquisas sobre o movimentos sociais em defesa da infância realizadas no curso de Doutorado em Educação na Universidade de São Paulo em 2019. 


\title{
EL “MOVIMENTO INTERFÓRUNS DE EDUCAÇÃO INFANTIL DO BRASIL (MIEIB)” E SUS EFECTOS EN LAS POLÍTICAS PÚBLICAS
}

\begin{abstract}
RESUMEN: Este artículo analiza cómo el "Movimento Interfóruns de Educação Infantil do Brasil (MIEIB)" buscó incidir en las políticas públicas del área. Se discute cómo se organiza el movimiento, sus estrategias, sus avances y desafíos en su relación con el gobierno federal a lo largo de sus 20 años. La recolección de datos se dio a través de investigación documental y entrevista en profundidad. Se destacan las teorías que discurren sobre las consecuencias de los movimientos sociales en las políticas públicas, de autores como Edward Amenta, Alberto Melucci e Theda Skocpol, entre otros. Se concluye que las posibilidades de incidencia de los movimientos sociales en la política están marcadas por las relaciones socioestatales establecidas, que varían según la combinación de objetivos y capacidades de acción tanto del Estado como del movimiento social.

Palabras-clave: Movimientos Sociales. Movimento Interfóruns de Educação Infantil do Brasil. Educación Infantil. Políticas Públicas. Interacciones Socioestatales.
\end{abstract}

\section{Introdução}

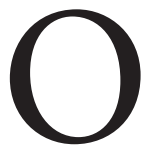

s efeitos dos movimentos sociais nas políticas públicas têm sido um proeminente campo de estudos na literatura movimentista. Autores de diferentes correntes teóricas, como Amenta (2006), Andrews (2001), Mellucci (1999), Meyer (2007), Skocpol (1995) e Snow e Benford (1988), estudaram esses efeitos e sua causalidade. Com base em tais estudos, este artigo procura compreender como o Movimento Interfóruns de Educação Infantil do Brasil (MIEIB) afetou as políticas para a área, analisando as estratégias do movimento e as relações estabelecidas com o Estado no âmbito do governo federal.

A rede MIEIB é composta por fóruns autônomos de educação infantil espalhados pelo Brasil. Todos os 26 estados, além do Distrito Federal, possuem fóruns. Além destes, existem aproximadamente 41 fóruns municipais ou regionais de educação infantil no país, cada um com sua própria forma de organização e funcionamento, a depender do contexto em que está inserido. Apesar da autonomia, há identidade de princípios e bandeiras comuns entre eles.

Três dimensões de estratégias de atuação marcam a rede MIEIB. São elas:

1. Propositiva: proposição e acompanhamento das diretrizes, políticas e ações relacionadas à educação infantil nas diferentes esferas governamentais e âmbitos de atuação (municipal, estadual e nacional);

2. Mobilizadora: articulação de parcerias, ampliação e fortalecimento dos fóruns;

3. Formativa: organização, sistematização, publicação e divulgação dos avanços das pesquisas nos diferentes campos do saber, nos subsídios às redes de educação infantil e na formação dos profissionais ligados à área.

Neste artigo, o foco são as ações do MIEIB nas políticas para a área em âmbito nacional. O movimento teve início no ano de 1999, como uma articulação de sete fóruns estaduais de educação infantil (São Paulo, Minas Gerais, Rio de Janeiro, Ceará, Paraná, Santa Catarina e Mato Grosso do Sul) que buscavam potencializar sua atuação juntando esforços e consensos entre si. Os fóruns, por sua vez, surgiram na década de 1990, após o período de redemocratização do país, em que floresceram diversas 
inovações democráticas de participação e controle social. São movimentos sociais híbridos que contam com a adesão de diferentes atores e organizações sociais interessados no debate e na reivindicação de direitos relativos a temáticas específicas. No caso da educação infantil, a criação dos fóruns se deu pela demanda decorrente das intensas mudanças legislativas ocorridas na área, como a inclusão dessa etapa como educação básica na Lei de Diretrizes e Bases da Educação Nacional (LDB, Lei n 9.394/96). Muitos estados e municípios passaram a organizar encontros para a discussão de políticas para a área, nos quais movimentos sociais, entidades e pesquisadores, que se vinham fortalecendo desde o processo constituinte, integraram-se, transformando esses espaços em novas arenas de luta e reivindicação de direitos.

O MIEIB é uma organização autônoma, de caráter interinstitucional e suprapartidário, cuja missão é:

\begin{abstract}
Contribuir para a universalização e efetivação do direito à educação com qualidade e equidade para as crianças de 0 até 6 de idade nos sistemas públicos de educação, por meio do fortalecimento da atuação da Rede MIEIB, em um contexto dialógico e democrático de participação, e da incidência política e de controle social das políticas públicas de Educação Infantil (MOVIMENTO INTERFÓRUNS DE EDUCAÇÃO INFANTIL DO BRASIL, 2017).
\end{abstract}

Em nível nacional, o movimento é formado por um comitê diretivo que conta com dez pessoas (cinco titulares e cinco suplentes) e uma secretária executiva. Em sua composição há dois representantes de fóruns de cada região do Brasil, sendo um titular e um suplente. O objetivo é manter o vínculo entre o movimento nacional e os fóruns, garantindo a retroalimentação entre eles. Às integrantes do comitê diretivo cabe, fundamentalmente, representar o MIEIB nas diversas ações, propor a agenda do movimento, acompanhar o planejamento e a execução das ações previstas, decidir alterações caso necessário e acompanhar a gestão financeira.

Os recursos do MIEIB têm sido historicamente obtidos por meio da apresentação de projetos a fundações e organizações não governamentais relacionadas à defesa da infância, como a Fundação Orsa, o Instituto Girassol, o Centro de Cultura Luiz Freire, a Terre des Hommes e o Instituto C\&A. Em geral, os recursos são destinados para o pagamento de transporte, alimentação e estadia das militantes ${ }^{1}$ e para o pagamento da secretaria executiva. Durante os governos do presidente Lula (2003-2011) e da presidenta Dilma Rousseff (2012-2016), o MIEIB também recebeu apoio de órgãos governamentais em ocasiões eventuais como pesquisas, projetos e eventos (LOPES, 2018, p. 70).

Para o levantamento dos dados sobre a atuação do MIEIB no âmbito das políticas nacionais e sua relação com o governo federal desde seu surgimento até o ano de 2018, partiu-se das pesquisas já realizadas (CANAVIEIRA, 2010; FLORES, 2010; NUNES, 2010). Devido à dificuldade em conseguir documentos mais antigos do movimento, como atas e registros internos, especialmente os referentes à sua primeira década e meia de existência, foram utilizados como fonte os documentos públicos e as cartas de posicionamento. Os encontros nacionais do MIEIB ocorridos entre 2015 e 2017 foram transcritos em sua maior parte. Documentos oficiais da Coordenação de Educação Infantil (COEDI) do Ministério da Educação (MEC) e da Câmara de Educação Básica (CEB) do Conselho Nacional de Educação (CNE) foram analisados na busca de compreender como o movimento e os princípios por ele defendidos foram incorporados. Além da análise documental, duas militantes históricas foram ouvidas por meio de entrevistas semiestruturadas. 


\section{Os efeitos dos movimentos sociais nas políticas públicas: aproximações teóricas}

Duas vertentes teóricas têm sido comumente utilizadas para a análise do fenômeno dos movimentos sociais: a estadunidense e a europeia (ALONSO, 2009; CARLOS, 2012; GOHN, 2011). Tais vertentes surgiram e ganharam força analítica a partir da década de 1960, com o advento de novas formas de organização e estratégias por parte dos movimentos sociais e novas pautas reivindicatórias, como direitos civis, direitos ambientais e movimentos feministas.

Ao se referirem aos efeitos dos movimentos sociais, os estudiosos da vertente estadunidense defendem a ideia segundo a qual tais movimentos não apenas têm influência potencial nas políticas, mas podem ser veículos de mudança social. Obter acesso ao processo de tomada de decisão, alternar os objetivos e prioridades das instituições, assegurar políticas favoráveis garantindo que sejam implementadas e deslocar distribuição de recursos públicos para beneficiar seus constituintes são alguns dos efeitos da atuação dos movimentos, segundo esses pesquisadores.

Diversas explicações causais são apresentadas para a obtenção dos efeitos nas políticas, destacando-se a capacidade organizacional do movimento, as oportunidades e mediações políticas e os enquadramentos discursivos que os movimentos utilizam para expressar suas demandas.

De acordo com Andrews (2001), a capacidade organizacional de um movimento social pode influenciar o processo político por meio de sua estrutura organizacional, de sua estrutura de liderança e de seus recursos. A capacidade organizacional permite ao movimento empregar múltiplos mecanismos de influência, no qual se incluem a disrupção, a persuasão e a negociação. Uma estrutura de liderança permite a comunicação do movimento a distintos públicos, incluindo participantes, ativistas potenciais, opositores e atores estatais. Um movimento com infraestrutura forte possui uma estrutura de liderança complexa, com diversos líderes e "laços informais que atravessam fronteiras geográficas e sociais e uma base de recursos que atrai substancialmente as contribuições de seus membros, tanto para o trabalho quanto para o dinheiro" (ANDREWS, 2001, p. 76).

Por sua vez, Meyer e Staggenborg (1996) salientam a importância das oportunidades políticas para o efeito dos movimentos sociais. Elas acontecem quando os movimentos encontram disponibilidade de abertura para suas demandas nas autoridades governamentais. Essas oportunidades podem ser obtidas por meio de, entre outros fatores, protestos em massa, mudança de orientações políticas governamentais (por meio de eleições, por exemplo) ou eventos críticos², que chamem a atenção da mídia para as demandas do movimento. As características dos Estados e das instituições políticas, suas regras e procedimentos (incluindo a divisão de poder nos diferentes ramos do governo) influenciam as ações e efeitos dos movimentos sociais porque determinam os múltiplos pontos de acesso ou fechamento disponíveis.

Amenta (2006) atentou para as redes de relação construídas entre os movimentos sociais e as elites políticas, que, quando aliadas, podem auxiliar os movimentos por meio da minimização de obstáculos políticos e da abertura do sistema para suas demandas. A mobilização dos movimentos sociais requer atores que o apoiem e o legitimem nas instituições políticas ou em outros contextos institucionais (mediação política).

O modo como os movimentos sociais direcionam seu discurso e aproveitam as oportunidades discursivas existentes também são fatores importantes para seus efeitos, segundo os pesquisadores estadunidenses. Para Snow e Benford (1988), as frames são enquadramentos discursivos que ocorrem quando os ativistas articulam suas interpretações do problema social e político (frame diagnóstica), sua solução (frame prognóstica) e as razões pelas quais as pessoas devem apoiá-los (frame ressonante). 
Para ter sucesso com os legisladores, os ativistas precisam identificar ideias na cultura política maior que sejam realistas, legítimas e sensíveis a suas demandas. Os movimentos podem aproveitar o sistema de significado cultural mais amplo e articular frames que possam ecoar, amplificar e estender aspectos específicos de sua orientação ideológica (SNOW; BENFORD, 2000, p. 58-59). Além disso, as mudanças nas circunstâncias políticas e sociais podem promover oportunidades discursivas 3 mais voláteis e resultar em um clima mais propício para as demandas do movimento.

Enquanto a vertente estadunidense busca explicar os efeitos dos movimentos sociais para as políticas enfatizando sua capacidade organizacional, as oportunidades e mediação política e a articulação das frames, a vertente europeia traz outra importante contribuição para o debate: ao agirem e pressionarem os sistemas de autoridade para suas demandas, os movimentos sociais podem aprofundar a democracia pela ampliação do espaço público.

Dentro do contexto dos estudiosos europeus, o italiano Melucci (1999) afirmou que, ainda que os movimentos sociais não estejam voltados exclusivamente para a mudança política, podem provocá-la na medida em que produzem novos modelos organizacionais e padrões de comportamento que influenciam instituições e atores sociais públicos e privados. Eles fornecem novos formuladores de política, garantem a renovação do pessoal nas instituições estatais, criam novos padrões de comportamento e novos modelos de organização (MELUCCI, 1999, p. 56).

Segundo Melucci (1999), a emergência dos "novos movimentos sociais" que reivindicavam sobretudo pautas identitárias (como os movimentos feminista e negro) provocou um alargamento do espaço público, por meio do qual, diferentemente de institucionalizá-los dentro do enquadramento das instituições políticas (transformando-os em partidos, por exemplo), criou-se um espaço intermediário, em que suas demandas pudessem ser ouvidas e/ou transformadas em decisões políticas. Segundo o autor, se de um lado as formas de organização das instituições políticas tradicionais não respondiam às demandas coletivas, uma vez que não ouviam a voz dos movimentos e não conseguiam adaptar-se à pluralidade de seus atores e temas, por outro lado os movimentos sociais não poderiam sobreviver em sociedades complexas sem qualquer forma de representação política. A forma compreendida por Melucci (1999) como possível para que os movimentos sociais não se fragmentassem ou dispersassem foi a existência de canais de representação e de atores institucionais que pudessem traduzir a mensagem da ação coletiva em decisões. Os conselhos de área participativos no Brasil são exemplos desses canais.

Outra importante contribuição para o tema é a produção da socióloga Theda Skocpol (1995). Muitos estudiosos brasileiros que relacionam movimentos sociais e efeitos nas políticas públicas têm encontrado na produção da autora uma referência importante (GURZA LAVALLE et al., 2018). Segundo Skocpol, para entender o efeito dos movimentos sociais nas políticas é preciso compreender os pontos de acesso que estes obtêm para adentrar o Estado, criando e ocupando espaços de influência nos processos decisórios.

De acordo com Skocpol (1995), resultados políticos são gerados por atores cujos objetivos, capacidades e conflitos uns com os outros se baseiam nas instituições. Em sua visão, instituições não são apenas um conjunto de valores, normas e regras, mas sobretudo um conjunto de interações e padrões de comunicação e atividade. Na definição de Skocpol (1995), o Estado vai além de um cenário onde diversos grupos atuam, sendo compreendido pela autora como instituição e ator que, juntamente com outros atores, incide nos processos políticos.

Movimentos sociais são fenômenos complexos, no qual tanto as dimensões culturais e societárias quanto as relacionadas ao campo das instituições, dos governos e do Estado coexistem e se constituem em processos dinâmicos e interativos (CARLOS, 2012, p. 38). As esferas da sociedade e do Estado não são estanques e autônomas, mas constituídas de fronteiras fluídas e imprecisas, nas quais interagem e se 
influenciam mutuamente, afetando atores tanto da sociedade civil quanto das instituições governamentais.

Para que o movimento tenha mais probabilidade de alcançar seus objetivos, é preciso que ele estabeleça encaixes institucionais (pontos de acesso e influência) com o Estado. Instâncias de fiscalização, cogestão de serviços, criação de programas de políticas públicas ou ocupação de cargos são exemplos de encaixes que podem ser "tanto provocados por atores sociais quanto capacidades adquiridas pela atuação do Estado" (GURZA LAVALLE et al., 2018, p. 31-32).

Quando se reconhece a legitimidade de determinado ator social para agir na intermediação dos recursos públicos no atendimento a certos segmentos da população, ou seja, admitem-se suas esferas de competência na capacidade de agir em determinado âmbito seja ou não sob a responsabilidade direta do Estado, pode-se dizer que esse ator possui domínio de agência (GURZA LAVALLE et al., 2018). Os domínios de agência nas interações socioestatais não são dados a priori; são fruto de conflitos, processos de aprendizagem e cooperação, e "cada domínio responde a uma articulação de elementos produzidos em diferentes momentos: regulações, repertórios de ação considerados legítimos e capacidades de ação dos atores sociais e do Estado" (GURZA LAVALLE et al., 2018, p. 15).

$\mathrm{Na}$ construção de encaixes, três mecanismos funcionam de forma interdependente e complementar: institucionais, relacionais e sociais. Os institucionais referem-se às instituições políticas: composição partidária dos Poderes Executivo e Legislativo, permeabilidade do Estado e capacidades estatais em formular e implantar políticas. Os relacionais dizem respeito às articulações entre os movimentos sociais e sua rede de relações informais, de apoio e coalizões construídas ao longo do tempo, tanto com outros movimentos como com figuras do Estado nos diferentes Poderes. Finalmente, mecanismos sociais referem-se às capacidades de ação dos movimentos sociais em construir encaixes institucionais e domínios de agência, e que são expressas em suas formas de organização e nos repertórios de ação coletiva (GURZA LAVALE et al., 2018, p. 36).

\section{O Movimento Interfóruns de Educação Infantil do Brasil: estratégias de atuação, relações com o governo federal e incidências nas políticas}

Ao longo de sua trajetória de 20 anos, o MIEIB estabeleceu interações com o governo federal que facilitaram ou dificultaram suas ações na busca por influenciar as políticas da área de Educação Infantil em nível nacional. Ao analisar a trajetória do MIEIB, foi possível destacar quatro momentos históricos vividos pelo movimento: criação, consolidação, encaixes e desencaixes com o governo federal:

\section{$1^{\text {a }}$ fase: criação (1999-2002)}

Durante o período de seu surgimento, em 1999, até o ano de 2002, as ações do MIEIB voltaram-se principalmente ao fortalecimento do próprio movimento e à sua capilarização.

Ao longo desse período [1999-2002] de atividades constantes (encontros estaduais, reuniões de trabalho, intenso processo de articulação, elaboração de diferentes documentos), o MIEIB veio não apenas ampliando a participação de mais entidades e profissionais, através da criação de novos Fóruns, como, também, construindo sua identidade. Dessa forma, tem exercido papel político fundamental em defesa dos interesses da área, criando condições de assessoramento e apoio mútuo entre os Fóruns que o constituem, promovendo, ainda, a formação continuada dos participantes (MOVIMENTO INTERFÓRUNS DE EDUCAÇÃO INFANTIL DO BRASIL, 2002, p. 8). 
O MIEIB surgiu no início do segundo mandato do governo de Fernando Henrique Cardoso (19992002), presidente que em 1996 passou a adotar recomendações do Fundo Monetário Internacional (FMI), priorizando o ensino fundamental e retomando projetos informais de baixo custo para a educação infantil. Nesse contexto, apesar do foco do movimento em seu fortalecimento e ampliação, buscou-se construir concepções e práticas opostas ao caráter de tutela, assistencialismo e clientelismo que marcavam a área (NUNES, 2009).

A primeira grande mobilização nacional do MIEIB veio com a elaboração e entrega da Carta de Compromisso com a Educação Infantil aos candidatos à Presidência, em 2002.

\section{$2^{\mathrm{a}}$ fase: consolidação (2003-2006)}

Foi nos governos de Luiz Inácio Lula da Silva (2003-2006 e 2007-2010) e nos mandatos de Dilma Rousseff (2011 a 2014 e 2015 a 2016) que o MIEIB passou a incidir mais fortemente nas políticas públicas em âmbito nacional. Ainda como candidato, Lula comprometeu-se a reconhecer o MIEIB como interlocutor do governo federal na formulação da política educacional, assinando a carta-compromisso.

Assim que o presidente Lula assumiu, representantes do MIEIB, de posse da carta assinada, exerceram pressão por maior participação nas políticas públicas da área. Nessa época ocorria a integração efetiva das creches nos sistemas educativos. Embora na LDB n $9.394 / 96$ estivesse previsto que essa integração se daria após três anos de sua publicação, ela só passou a ocorrer efetivamente na maior parte dos municípios em 2003. Esse contexto facilitou ao MIEIB, que vinha se ampliando e legitimando, a sua inserção no debate.

Em 2003, o movimento - que já contava com 15 fóruns estaduais de educação infantil - passou a compor o Comitê Nacional de Políticas de Educação Básica (CONPEB) do MEC, órgão responsável por delinear políticas públicas de Educação. A integração nesse comitê possibilitou a participação do MIEIB na elaboração de documentos oficiais do MEC relacionados à educação infantil. Contudo, isso não impediu conflitos na relação com o Poder Executivo federal. Com o advento da discussão sobre o Fundo de Manutenção e Desenvolvimento do Ensino Fundamental e de Valorização do Magistério (FUNDEF), que em 2006 teria seu término de vigência de dez anos, veio o debate de ampliação do fundo para a educação infantil e o ensino médio. Todavia, a Proposta de Emenda Constitucional (PEC) no 415/2005 (BRASIL, 2005), apresentada pelo Poder Executivo à Câmara dos Deputados, excluía a creche da cobertura e deixava de fora os mecanismos de distribuição de recursos previstos nesse fundo para as crianças de 0 a 3 anos. Após o MIEIB e outros movimentos questionarem o governo sobre tal exclusão e não obterem resposta satisfatória, surgiu o Movimento Fraldas Pintadas, com o slogan: "Direito à educação começa no berço e é pra toda a vida". Juntamente com outros movimentos e entidades ${ }^{4}$, o MIEIB saiu em passeata em frente ao Congresso Nacional exigindo a inclusão do segmento de 0 a 3 anos no Fundo de Manutenção e Desenvolvimento da Educação Básica e de Valorização dos Profissionais da Educação $(\text { FUNDEB })^{5}$, o que mais tarde aconteceu, como fruto dessa pressão. Embora os protestos e marchas não fossem uma estratégia comumente utilizada pelo movimento, naquele momento foi uma das vias encontradas para pressionar o Executivo e os deputados federais.

Durante os dois governos de Luiz Inácio Lula da Silva, novos conselhos nacionais de políticas públicas foram criados e/ou fortalecidos, e mais de 70 conferências nacionais de diversas áreas foram realizadas (ABERS; SERAFIM; TATAGIBA, 2014, p. 325). Houve nesses mandatos maior aproximação com os movimentos sociais, o que provocou novos padrões de relações socioestatais, com formas inovadoras de comunicação e negociação. Nos governos Lula e Dilma, observou-se maior "trânsito institucional" aos movimentos sociais, trazendo maior abertura à sua participação, o que os legitimou frente às instâncias políticas e favoreceu a institucionalização de suas demandas (SILVA; OLIVEIRA, 2011). 
Outra forma de aproximação dos governos Lula e Dilma com os movimentos sociais foi a integração de ativistas em cargos comissionados. Esse foi o caso de Rita Coelho, que era integrante do Comitê Diretivo do MIEIB à época do início do segundo mandato do governo Lula e foi convidada, em 2007, para chefiar a COEDI do MEC.

\section{$3^{\mathrm{a}}$ fase: por dentro do governo (2007-2016)}

A partir da entrada de Rita Coelho no governo federal, o MIEIB passou a ter uma influência maior nas ações do MEC, por meio da contribuição, tanto da rede do movimento como um todo (comitê diretivo nacional e fóruns estaduais) quanto individualmente por parte de algumas de suas militantes reconhecidamente especialistas na área e professoras de universidades públicas no país - na elaboração de diversas políticas e publicações em nível nacional.

Essa evidência da participação do MIEIB nas publicações oficiais advindas tanto do MEC quanto do CNE é explicitada em documentos oficiais, nos documentos do próprio movimento e em pesquisas sobre o tema (CANAVIEIRA, 2010; FLORES, 2010; NUNES, 2010).

A publicação "Práticas cotidianas na educação infantil: bases para a reflexão sobre as orientações curriculares" (BRASIL; UNIVERSIDADE FEDERAL DO RIO GRANDE DO SUL, 2009), resultado de um convênio de cooperação técnica entre a COEDI do MEC e a Universidade Federal do Rio Grande do Sul, bem como o parecer que redefine as Diretrizes Curriculares Nacionais para a Educação Infantil (CONSELHO NACIONAL DE EDUCAÇÃO, 2009), são exemplos de documentos em cuja elaboração se explicitou nominalmente a participação da rede MIEIB.

A participação da rede MIEIB na elaboração de documentos oficiais revelou-se não apenas de forma textualmente explícita, mas também na inclusão dos enquadramentos discursivos (frames) defendidos e/ou reforçados pelo movimento como, por exemplo, a indissociabilidade entre cuidar e educar e a efetivação de projetos que promovam autonomia e multiplicidade de experiências para as crianças.

Além das publicações oficiais, o MIEIB incidiu diretamente na elaboração de políticas públicas para a educação infantil em âmbito nacional, como no caso, por exemplo, do programa Proinfância ${ }^{6}$ e da Política Nacional de Educação Infantil do Campo. Segundo uma das entrevistadas do comitê diretivo, o MIEIB participou de uma série de reuniões e integrou distintos comitês que trataram de diversos assuntos relacionados à área, tanto no âmbito da COEDI quanto no do Instituto Nacional de Estudos e Pesquisas Educacionais Anísio Teixeira (INEP), ou ainda na elaboração de portarias interministeriais.

Apesar da aproximação com a COEDI do MEC e com alguns outros ministérios com os quais foram confeccionadas portarias conjuntas ${ }^{7}$, no âmbito maior do governo a participação do MIEIB não se deu sem embates. Internamente, tanto nos governos de Lula quanto nos de Dilma, políticas diferenciadas para a educação infantil conviveram entre os diferentes ministérios e secretarias. Um exemplo foi a proposta da Secretaria de Assuntos Estratégicos (SAE) da Presidência da República para a utilização do instrumento estadunidense de avaliação das crianças em larga escala denominado Age \& Stages Questionnaires (ASQ-3) nas instituições de educação infantil brasileiras. Essa proposta foi rechaçada veementemente pelos fóruns de educação infantil, que apontaram os riscos desse tipo de avaliação e criaram um abaixo-assinado na busca de contê-la (ARELARO; MAUDONNET, 2017). Em 2012 foi criado o Grupo de Trabalho (GT) para Avaliação da Educação Infantil, com a participação do MIEIB, entre outras entidades. Esse GT salientou, ao contrário da proposta da SAE, que a avaliação na educação infantil deveria ser institucional e não do desenvolvimento das crianças. Esse exemplo demonstra que repertórios de interação entre Estado e movimento acontecem por meio de relações com governos que quase nunca são homogêneos. 
O fato do MIEIB ter uma ex-militante na chefia da COEDI do MEC promoveu maior participação do movimento na elaboração de documentos oficiais e em comissões de discussão de políticas públicas para a área. Na visão de Abers, Serafim e Tatagiba (2014), ter um integrante ocupando posições no governo facilita as conexões entre os atores estatais e não estatais, na medida em que os movimentos passam a ter conexões mais personalizadas. Contudo, atentam as autoras, o fato de os movimentos sociais adentrarem o Estado não significa necessariamente que haverá o atendimento de sua agenda em curto prazo ou a ampliação dos direitos sociais por eles reivindicados.

Abers e Tatagiba (2016) afirmam que o aceite de cargo nos quadros de governo é uma situação de encaixe, nos termos de Scokpol (1995), o que não quer dizer que o movimento se desmobilizará ou deixará de adotar outras táticas de intervenção. Trata-se, na visão dos autores, de uma forma de "ativismo institucional", no qual o sujeito permanece, submetido às regras daquele espaço institucional, enquanto o contexto político é favorável. Após a entrada de Rita Coelho na COEDI/MEC, não se têm notícia de protestos ou posicionamentos públicos contrários às políticas desse órgão. O que se observou foram pressões e posicionamentos do MIEIB endossados pela COEDI e vice-versa, quando existiam propostas de políticas de outras secretarias e departamentos do governo federal que se opunham às defesas do movimento, como é o caso já citado do apoio da SAE ao instrumental de avaliação ASQ-3.

Quando um militante assume um cargo no governo, tanto ele quanto o próprio movimento são impactados. Para o sujeito, há o desafio entre ser fiel aos princípios do movimento e por vezes assumir políticas contraditórias a ele, considerando que os governos não são homogêneos e envolvem disputas internas de poder e relações de alianças. Para os integrantes do movimento, há a contradição entre estar integrado ao governo por meio de um representante e fazer um questionamento público explícito relevando as contradições da política sem enfraquecer seu representante nas disputas governamentais internas.

\section{$4^{\mathrm{a}}$ fase: desencaixes com o governo federal (2016-2018)}

Segundo Meyer e Staggenborg (2007), resultados eleitorais podem representar mudanças de alinhamento entre governo e movimento social e podem constituir-se tanto como uma oportunidade política para movimentos se inserirem e incidirem mais diretamente nas políticas públicas ou como obstáculos para tais ocorrências. O mesmo caso se aplica a um processo de impeachment em que novas forças políticas assumem o poder.

Após o impeachment de Dilma Rousseff em 2016, Rita Coelho foi desligada do cargo de chefia da COEDI, que passou a ter menor autonomia na decisão de políticas públicas. Um novo contexto se instalou e as políticas que passaram a ser impostas desconsideraram muitos dos avanços da área e dificultaram o diálogo com as militantes do movimento, as associações científicas e os sindicatos.

Entre os anos de 2016 e 2018, vários foram os posicionamentos públicos do MIEIB contrários às políticas do governo Michel Temer (2016 a 2018) destinadas à Educação e à infância, como no caso do Programa Criança Feliz, no âmbito do Ministério do Desenvolvimento Social. Instituído nos primeiros meses do novo governo, o projeto sinalizava a volta de propostas de programas "não formais", com baixo investimento público, para a infância brasileira, nos moldes do defendido anteriormente pelo presidente Fernando Henrique Cardoso.

As medidas tomadas pelo governo de Michel Temer por meio de decretos-leis, medidas provisórias e projetos de emendas constitucionais, contrárias às bandeiras de luta do movimento, impulsionaram o MIEIB a fortalecer as parcerias com outras entidades ligadas à área de Educação e atentar para a necessidade de ampliar suas parcerias com movimentos sociais com bandeiras mais abrangentes, como os movimentos 
de mulheres, defensores de direitos humanos e das minorias em geral. Apesar de historicamente o MIEIB ter a estratégia de articulação com outros movimentos sociais e entidades, essas parcerias vinham-se centrando em grupos ligados à Educação e à infância, como observou Nunes (2010).

Em 2017, o movimento criou o Projeto de Fortalecimento Institucional, com o objetivo de amplificar sua incidência. Tal projeto teve na elaboração do Plano de Sustentabilidade sua principal ação. Esse plano seguia os eixos de atuação do movimento, divididos em sete aspectos:

1. Articulação do MIEIB com os fóruns, a sociedade civil e os governos;

2. Formação política;

3. Comunicação;

4. Documentação das ações e dos resultados;

5. Advocacy;

6. Monitoramento das políticas públicas;

7. Gestão e estrutura organizacional.

$\mathrm{Na}$ análise do plano, observa-se que, embora houvesse a permanência de estratégias e táticas historicamente utilizadas, ampliações táticas foram sugeridas. Dentre as estratégias e táticas comumente utilizadas estavam: a articulação de parcerias, a representação do MIEIB em diversos espaços institucionais, a criação e o fortalecimento dos fóruns de educação infantil, a formação político-pedagógica para a rede MIEIB, os posicionamentos públicos, a organização e participação de uma diversidade de encontros da área e audiências públicas no Legislativo e a elaboração de cartas-compromisso a serem entregues e assinadas por candidatos aos Poderes Executivo e Legislativo.

Assim como as estratégias e táticas rotineiras, a ampliação de opções táticas proposta no Plano de Sustentabilidade estava voltada tanto para a audiência interna (membros dos fóruns) quanto para a externa (simpatizantes, formuladores de políticas públicas e público em geral). Entre as propostas de ampliação tática evidenciou-se a maior divulgação e utilização de novas ferramentas tecnológicas (como a ampliação do site para maior participação dos fóruns), a criação de podcasts e de um canal no Youtube, a divulgação de clipping de notícias para subsidiar jornalistas e parlamentares, a criação de um banco de dados para monitoramento tanto das proposições legislativas quanto das notícias nos meios de comunicação sobre a educação infantil e a criação do GT Incidência Política para elaboração de posicionamentos públicos a serem discutidos e validados pela rede do MIEIB.

No âmbito do MIEIB, as estratégias têm-se constituído naquilo que Tilly (1993) definiu como “estoque cultural". Para o autor, apesar das múltiplas possibilidades de ação coletiva, há um repertório estrutural e cultural sobre como agir e se organizar em determinadas situações, que é utilizado pelos movimentos sociais ao longo de sua trajetória. Fatores internos e externos são capazes de afetar as escolhas táticas e provocar constrangimento nas opções. Entre esses fatores, destacam-se os valores subjacentes ao movimento, seus princípios morais, sua forma de organização e identidade, a forma como o público (simpatizantes e adversários) o vê e os recursos materiais e humanos disponíveis.

Historicamente, o MIEIB tem defendido o debate democrático e assim é percebido por seu público. Nesse sentido, táticas como posicionamentos públicos, participação em audiências públicas e comissões mistas (governo e sociedade civil) para elaboração de políticas públicas têm sido preferencialmente utilizadas ao longo de sua trajetória. Contudo, mudanças táticas podem ocorrer devido às alterações nos contextos nos quais os movimentos sociais são incorporados. Três fatores contribuem para que haja inovação tática: (1) alteração na estrutura social ou na estrutura de autoridade; (2) emergência de novos movimentos que constroem outras táticas ao perceberem que as convencionais não são mais capazes de atingir seus interesses; (3) ocorrência de novas ferramentas tecnológicas (SNOW; SOULE, 2010). 
McAdam (1983) definiu inovação tática como um processo interativo de inovação e adaptação em razão dos desafios e dos adversários. Isso significa que, embora o MIEIB historicamente se tenha utilizado de um repertório limitado de táticas, o novo contexto que se apresentou a partir do impeachment da presidenta Dilma Rousseff parece ter provocado no movimento a necessidade de criação de novas possibilidades de atuação, na busca de maior incidência.

O diálogo e a negociação com os governos têm sido estratégias do MIEIB. Porém, o novo contexto pós-impeachment dividiu as posições dentro do movimento. Enquanto algumas militantes defenderam a posição de que dialogar com representantes do governo de Michel Temer seria reconhecê-lo como legítimo após o golpe institucional, outras reafirmaram a necessidade da manutenção do diálogo enquanto característica do movimento, na perspectiva de uma "resistência por dentro".

Decidir-se por outra estratégia de incidência política traz dilemas para os atores dos movimentos sociais, uma vez que as escolhas definem quem são os aliados potenciais, os espectadores, seus alvos e oponentes (MEYER, 2007). Estabelecer diálogo com representantes de um governo de oposição pode trazer o risco de tal governo utilizar-se dessa abertura como legitimação para suas políticas. Por outro lado, a discordância interna em relação à estratégia a ser utilizada pode provocar cisões e rupturas. No caso do MIEIB, os descontentamentos com os rumos do movimento e/ou o não atendimento de suas demandas têm provocado o afastamento de alguns membros. Esses afastamentos, demandas e divergências merecem atenção e precisam ser acolhidos pelo comitê diretivo (CD). Nenhum movimento está livre de que dissidências provoquem sua ruptura, o que pode ocorrer se não houver um debate interno democrático, transparente e participativo e se o CD se afastar dos princípios comuns que garantem sua unidade.

\section{Considerações finais}

Os encaixes institucionais, marcados pelo acesso mais perene ao Estado, assim como os desencaixes, quando esse acesso é dificultado, provocam distintas ações estratégicas dos movimentos sociais. Decidir por uma ou outra estratégia historicamente utilizada ou buscar inovações táticas pode influenciar sua incidência nas políticas públicas; mas, para isso, ao elegerem as que consideram mais eficientes, os ativistas precisam ter em conta seus riscos e benefícios, analisando o contexto de interação entre o movimento e as relações de força presentes tanto no âmbito do Estado quanto no interior do movimento e nas possibilidades de coalizão que se apresentam. Decidir sobre as arenas de atuação e as estratégias de incidência em cada uma delas, refletir sobre as alianças a serem realizadas e seus impactos para seu público-alvo (formuladores e legisladores de política, membros e simpatizantes do movimento) são algumas das tarefas permanentes e necessárias a todo movimento social.

Dos 20 anos de atuação do movimento nacional, em 14 deles o MIEIB estabeleceu um domínio de agência dentro da política de educação infantil. O movimento foi legitimado pelos governos de Lula e Dilma como relevante para a definição de políticas públicas na área. Além da presença da Rita Coelho, militante do MIEIB, na chefia da Coordenadoria de Educação Infantil do MEC, várias publicações oficiais incluíram a participação do movimento tanto no nível do MEC como em documentos de outros ministérios e no âmbito do CNE.

Com o impeachment de Dilma Rousseff no ano de 2016, houve a entrada de um novo grupo no poder, que, ao contrário dos governos anteriores, deslegitimou a participação e a incidência dos movimentos sociais, provocando um desencaixe do MIEIB com o governo federal. Esse novo contexto fez com que o MIEIB fortalecesse e ampliasse suas articulações com outros movimentos sociais e entidades relacionadas à Educação, criasse inovações táticas e procurasse novas formas de se relacionar com o Estado. 
O MIEIB é um movimento bem estruturado, com princípios e bandeiras públicas definidas e bastante capilarizado. Desde seu surgimento, obteve importantes conquistas para a área de educação infantil no país. Contudo, ainda permanece o desafio da manutenção e consolidação das normativas legais nas redes de educação.

Tais desafios têm-se intensificado após a entrada do presidente Jair Bolsonaro no governo federal. Vários conselhos participativos foram fechados por decreto federal, dificultando a participação e o monitoramento das políticas públicas por parte dos movimentos sociais e outras entidades da sociedade civil. A política do governo Bolsonaro desvaloriza e desestimula a pesquisa, o pensamento crítico e os espaços públicos de debate democrático, o que impõe a necessidade de aprofundamento da formação política dentro do MIEIB e a ampliação do diálogo com a população em geral.

Com um Poder Executivo fechado à participação, é preciso ampliar as articulações com outras dimensões do Estado, buscando aliados em outros setores estatais como o Legislativo e o Judiciário, para reafirmar a democracia e os avanços legais conquistados. A criação de novos fóruns precisa estar no horizonte do movimento, de modo a pressionar e ampliar também a defesa dos direitos das crianças brasileiras nos governos em nível municipal e estadual.

\section{Notas}

1. Neste trabalho, o uso do feminino ao se referir às militantes da rede MIEIB justifica-se, uma vez que as mulheres representam cerca de $90 \%$ dos comitês diretivos dos fóruns e do movimento nacional (MAUDONNET, 2019).

2. Eventos críticos podem ser eventos inesperados como crimes e acidentes, decisões no Tribunal de Justiça ou o lançamento de uma política.

3. Segundo Ferree (2003, p. 309), decisões judiciais, princípios constitucionais prévios que as invocam e legislações subsequentes são exemplos de oportunidade discursiva.

4. Campanha Nacional pelo Direito à Educação, Confederação Nacional dos Trabalhadores em Educação (CNTE), Fundação Abrinq, Conselho Nacional dos Direitos da Criança e do Adolescente (CONANDA), Marcha Mundial de Mulheres, Articulação de Mulheres Brasileiras, Instituto Ethos de Empresas e Responsabilidade Social, União Nacional dos Dirigentes Municipais de Educação (UNDIME) e Frente Parlamentar da Criança e do Adolescente.

5. O FUNDEB foi criado em 2006, em substituição ao FUNDEF, que surgiu em 1996 e vigorou de 1998 a 2006.

6. O Programa Nacional de Reestruturação e Aquisição de Equipamentos para a Rede Escolar Pública de Educação Infantil (Proinfância) foi uma ação do MEC com o objetivo de ampliar o acesso de crianças em creches e escolas, "bem como a melhoria da infraestrutura física da rede de Educação Infantil". Disponível em: $<$ http://www.fnde.gov.br/programas/proinfancia $>$. Acesso em: 19 jan. 2018.

7. Caso do Ministério da Saúde, na Portaria Ministerial da Associação Nacional de Vigilância Sanitária (ANVISA) que normatiza aspectos do atendimento oferecido nos estabelecimentos de educação infantil.

\section{Referências}

ABERS, R.; SERAFIM, L.; TATAGIBA, L.. Repertórios de interação Estado sociedade em um Estado heterogêneo: a experiência na era Lula. Dados, Rio de Janeiro, v. 57, n. 2, p. 325-357, 2014. https://doi. org/10.1590/0011-5258201411

ABERS, R.; TATAGIBA, L.. Institutional activism: mobilizing for women's health from inside the Brazilian bureaucracy. In: ROSSI, Federico; BÜLOW, Marisa. Social movement dynamics: new perspectives on theory and research from Latin America. London: Routledge, 2016. p. 73-104. 
ALONSO, A. As teorias dos movimentos sociais: um balanço do debate. Lua Nova, São Paulo, n.76, p. 49-86, 2009. https://doi.org/10.1590/S0102-64452009000100003

AMENTA, E. When movements matter: the thousand plan and the rise of social security. Princenton, NJ: Princenton University Press, 2006.

ANDREWS, K. T. Social movements and policy implementation: the Mississippi Civil Rights Movement and the war on poverty, 1965-1971. American Sociological Review, Washington, DC, v. 66, p. 71-95, 2001. https://doi.org/10.2307/2657394

ARELARO, L. R. G.; MAUDONNET, J. V. M. Os fóruns de educação infantil e as políticas públicas para a infância no Brasil. Revista Laplage, São Carlos, v. 3, n. 1, p. 6-18, 2017. https://doi.org/10.24115/ S2446-6220201731238p.6-18

BRASIL. Lei $n^{\circ}$ 9.394, de 20 de dezembro de 1996. Estabelece as diretrizes e bases da educação nacional. Brasília, DF, 1996. Disponível em: <http://www.planalto.gov.br/ccivil_03/leis/19394.htm>. Acesso em: 4 dez. 2019.

BRASIL. Ministério da Educação. Secretaria de Educação Básica; UNIVERSIDADE FEDERAL DO RIO GRANDE DO SUL. Práticas cotidianas na educação infantil: bases para reflexão sobre as orientações curriculares. Projeto de Cooperação Técnica MEC/UFRGS para Construção de Orientações Curriculares para a Educação Infantil. Consultoria de Maria Carmen Silveira Barbosa. Brasília, DF: MEC/SEB/UFRGS, 2009. Disponível em: <http://portal.mec.gov.br/dmdocuments/relat_seb_praticas_cotidianas.pdf >. Acesso em: 4 dez. 2019.

BRASIL. Poder Executivo. Proposta à Emenda Constitucional no 415, de 12 de maio de 2005. Dá nova redação ao $\$ 5^{\circ}$ do art. 212 da Constituição Federal e ao art. 60 do Ato das Disposições Constitucionais Transitórias. Brasília, DF, 2005. Disponível em: <https://www.camara.leg.br/proposicoesWeb/prop_mostra rintegra? codteor=1234517>. Acesso em: $10 \mathrm{dez} .2018$.

CANAVIEIRA, F. O. A educação infantil no olho do furacão: o movimento político e as contribuições da sociologia da infância. 2010. Dissertação (Mestrado em Educação) - Faculdade de Educação, Universidade Estadual de Campinas, Campinas, 2010.

CARLOS, E. Movimentos sociais e instituições participativas: efeitos organizacionais, relacionais e discursivos. 2012. Tese (Doutorado em Ciência Política) - Faculdade de Filosofia, Letras e Ciências Humanas, Universidade de São Paulo, São Paulo, 2012.

CONSELHO NACIONAL DE EDUCAÇÃO. Câmara de Educação Básica. Parecer nº 20/2009. Revisão das Diretrizes Curriculares Nacionais para a Educação Infantil. Aprovado em 11 nov. 2009. Brasília, DF, 2009.

FERREE, M. M. Resonance and radicalism: feminist abortion discourses in Germany and the United States. American Journal of Sociology, Chicago, IL, v. 109, n. 2, p. 304-344, 2003. https://doi.org/10.1086/378343

FLORES, M. L. R. Movimentos na construção do direito à educação infantil: histórico e atualidade. Revista Educação (UFSM), Santa Maria, v. 35, p. 25-38, 2010.

GOHN, M. G. Teorias dos movimentos sociais: paradigmas clássicos e contemporâneos. São Paulo: Loyola, 2011. 
GURZA LAVALLE, A. et al. Movimentos sociais e institucionalização: políticas sociais, raça e gênero no Brasil pós-transição. São Paulo: Centro de Estudos da Metrópole, 2018.

LOPES, T. A. C. F. O Programa de Reestruturação e Aquisição de Equipamentos para a Rede Escolar Pública de Educação Infantil - Proinfância: expansão da educação infantil com qualidade? 2018. Tese (Doutorado em Educação) - Faculdade de Educação, Universidade de São Paulo, São Paulo, 2018.

MAUDONNET, J. V. M. Movimentos sociais em defesa da infância: os fóruns de educação infantil e suas incidências nas políticas públicas no Brasil. 2019. Tese (Doutorado em Educação) - Faculdade de Educação, Universidade de São Paulo, São Paulo, 2019.

McADAM, D. Tactical innovation and the pace of insurgency. American Sociological Review, Washington, DC, v. 48, p. 735-754, 1983. https://doi.org/10.2307/2095322

MELUCCI, A. The new social movements: a theoretical approach. Social Science Information, [s. 1.], v. 19, n. 2, p. 199-226, 1980. https://doi.org/10.1177/053901848001900201

MELUCCI, A. Acción colectiva, vida cotidiana y democracia. México, DF: El Colégio de México, 1999.

MEYER, D. S. The politics of protest: social movements in America. New York: Oxford University Press, 2007. https://doi.org/10.1086/230869

MEYER, D. S.; STAGGENBORG, Suzanne. Movements, countermovements, and the structure of political opportunity. American Journal of Sociology, Chicago, IL, v. 101, p. 1.628-1.660, 1996.

MEYER, D. S.; STAGGENBORG, Suzanne. Thinking about strategy. Paper presented at the workshop Movement Cultures, Strategies and Outcomes. Hempstead, NY: Hofstra University, 9 abr. 2007.

MOVIMENTO INTERFÓRUNS DE EDUCAÇÃO INFANTIL DO BRASIL. Educação infantil: construindo o presente. Campo Grande, MS: EdUFMS, 2002.

MOVIMENTO INTERFÓRUNS DE EDUCAÇÃO INFANTIL DO BRASIL. Plano de fortalecimento institucional. [s. 1.], 2017.

NUNES, Deise G. Educação infantil e cultura política: um estudo sobre o Movimento Interfóruns de Educação Infantil Brasileiro - MIEBI. In: SEMINÁRIO LATINOAMERICANO DE ESCUELAS E TRABAJO SOCIAL, 19., 4-8 oct 2009, Ecuador. Anais... Guayaquil: Universidad Católica Santiago de Guayaquil, 2009.

NUNES, D. G. O Movimento Interfóruns de Educação Infantil: a construção de uma identidade cultural e política. In: REUNIÃO ANUAL DA ANPED, 33, Caxambu, 2010. Anais... Rio de Janeiro: ANPED, 2010.

SILVA, M. K.; OLIVEIRA, G.e L. A face oculta(da) dos movimentos sociais: trânsito institucional e intersecção Estado-movimento - uma análise do movimento de economia solidária no Rio Grande do Sul. Sociologias, Porto Alegre, ano 13, n. 28, p. 86-124, set./dez. 2011. https://doi.org/10.1590/S1517-45222011000300005

SKOCPOL, T. Why I am an historical institutionalist source. Polity, [s. 1.], v. 28, n 1, p. 103-106, 1995. https:// doi.org/10.2307/3235190

SNOW, D.; BENFORD, R. D. Clarifying the relationship between framing and ideology: comment on Oliver and Johnston. Mobilization, [s. 1.], v. 5, n. 1, p. 55-60, 2000. 
SNOW, D.; BENFORD, R. D. Ideology, frame resonance, and participant mobilization. International Social Movement Research, [s. 1.], v. 1, p. 197-217, 1988.

SNOW, D.; SOULE, S. A primer in a social movement. New York: Norton, 2010.

TILLY, C. Contentious repertoires in Great Britain, 1758-1834. Social Science History, [s. 1.], v. 17, p. $253-$ 280, 1993. https://doi.org/10.1017/S0145553200016849

\section{Sobre a Autora}

Janaina Vargas de Moraes Maudonnet é doutora em educação pela Universidade de São Paulo, especialista em Políticas Públicas para a Infância pela Organização dos Estados Ibero Americanos (OEI) e em Ética, Cidadania e Direitos Humanos na Educação pela Universidade Complutense de Madri. Foi pesquisadora visitante no Centro de Estudos da Democracia na Universidade da Califórnia Irvine.

Recebido: 27 Maio 2019 Aceito: 17 Jan 2020 